\title{
Circulating Levels of High-sensitivity C-reactive protein are Associated with Intra-plaque Neovascularization and Intra-plaque Hemorrhage as Evaluated by Contrast-enhanced Ultrasonography and Magnetic Resonance Imaging
}

\author{
Hana Ogura ${ }^{1}$, Takahiro Shimizu ${ }^{1}$, Masashi Hoshino ${ }^{1}$, \\ Kagehiro Uchida ${ }^{2}$, and Yasuhiro Hasegawa ${ }^{1}$
}

(Received for Publication: July 28, 2016)

\begin{abstract}
Background: Intra-plaque hemorrhage in carotid atheromatous plaque is a recognized high-risk state for ischemic events. Intra-plaque neovascularization can now be visualized by contrast-enhanced carotid ultrasonography (CEUS). These neovessels appear prone to rupture and may be a marker for high-risk of intra-plaque hemorrhage. This study aimed to investigate relationships among circulating biomarkers associated with carotid plaque instability and the presence of intra-plaque hemorrhage on magnetic resonance imaging (MRI) and intraplaque neovascularization on CEUS in patients with advanced atherosclerotic plaques.

Methods: Fifty-one patients with mild to severe carotid stenosis were prospectively enrolled, and carotid ultrasonography, CEUS, and MRI were performed. Circulating levels of soluble lectin-like oxidized low-density lipoprotein receptor-1 (sLOX-1), pentraxin 3 (PTX3), myeloperoxidase (MPO), matrix metalloproteinase (MMP)-9, and high-sensitivity- C-reactive protein (hs-CRP) were also measured.

Results: Carotid plaques were categorized into 3 groups based on MRI findings: fibrous tissue, $n=13$; lipid/ necrotic core, $n=30$; and intra-plaque hemorrhage, $n=8$. Regarding plaque echogenicity, 24 plaques were hypoechoic, and 27 were non-hypoechoic. Intra-plaque neovascularization on CEUS was observed in 14 plaques. Multivariate logistic regression analysis identified hypoechoic plaque (odds ratio, 63.126; 95\% confidence interval, 1.102-3616.91) and serum hs-CRP $(1.064 ; 1.002-1.130)$ as factors significantly associated with intra-plaque hemorrhage. Hypoechoic plaque $(30.362 ; 2.462-374.37)$, and serum hs-CRP (1.066; 1.003-1.132) were revealed as factors significantly associated with intra-plaque neovascularization.

Conclusions: Hypoechoic plaque and hs-CRP levels were identified as common predictors of intra-plaque hemorrhage and intra-plaque neovascularization. Longitudinal studies are warranted to clarify the roles of intra-plaque neovascularization on CEUS and hs-CRP levels in intra-plaque hemorrhage and ischemic stroke.
\end{abstract}

Key words

unstable plaque, carotid ultrasound, black-blood, biomarker

\section{Subject Terms}

Biomarker, Magnetic Resonance Imaging, Ultrasound, Cerebrovascular Disease, Stroke

\section{Introduction}

The presence of atherosclerotic plaques in the carotid artery is an important risk factor for cerebral infarction ${ }^{1)}$. Evaluation of carotid plaque vulnerability has been performed by carotid ultrasonography or magnetic resonance imaging (MRI). Hypoechoic plaque on carotid ultrasound and a lipid core and/or in-

1 Department of Internal Medicine, Division of Neurology, St. Marianna University School of Medicine, Kanagawa, Japan

2 Biomarker Science, Kyoto, Japan 
tra-plaque hemorrhage on MRI are features that are well- known to be highly associated with vulnerable plaques $^{2-4)}$. In particular, the presence of intra-plaque hemorrhage on MRI is currently recognized as a high-risk state for ischemic events resulting from plaque destabilization ${ }^{5-7)}$. Several histopathological studies demonstrated that intra-plaque neovascularization is observed in advanced atherosclerotic lesions and these neovessels could be prone to rupture ${ }^{899}$. The presence of intra-plaque neovascularization can now be evaluated by contrast-enhanced ultrasonography (CEUS), which may be useful for the characterization of both vulnerable carotid plaque feature ${ }^{10}$ and luminal stenosis. However, whether the presence of intraplaque neovascularization is a biomarker directly predictive of intra-plaque hemorrhage remains uncertain. In addition to imaging biomarkers, various circulating biomarkers such as high-sensitivity C-reactive protein (hs-CRP) ${ }^{1112)}$, pentraxin 3 (PTX-3) ${ }^{13)}$, and soluble lectin-like oxidized low-density lipoprotein receptor 1 (sLOX-1) ${ }^{14)}$ are known to be associated with vascular inflammation and plaque instability. Matrix metalloproteinase 9 (MMP-9) ${ }^{15) 16}$ ) and myeloperoxidase (MPO) $)^{17)}$ are known to be associated with plaque destabilization, rupture, or erosion. No information has been published regarding the difference in risk profiles including these circulating biomarkers between intra-plaque hemorrhage and intra-plaque neovascularization. Therefore, the aim of the present study was to investigate relationships between the above circulating biomarkers and the presence of intra-plaque hemorrhage on MRI and intra-plaque neovascularization on CEUS in patients with advanced atherosclerotic plaques.

\section{Patients and Methods}

\section{Study population}

Fifty-one patients (43 men, 8 women; mean age, $73.6 \pm 9.34$ years) with mild to severe carotid stenosis on carotid ultrasonography ( $\geq 50 \%$ in cross-sectional area) diagnosed from April 2013 to May 2015 were prospectively enrolled in this study. Based on clinical data including neuroimaging data, the ischemic stroke subtype was diagnosed on admission according to the Trial of ORG 10172 in Acute Stroke Treatment classification as: 1) large-artery atherosclerosis, 2) cardioembolism, 3) small-vessel occlusion, 4) stroke of other determined etiology, and 5) stroke of undetermined etiology ${ }^{18)}$. The exclusion criteria were 1) serious concurrent disease, 2) ischemic stroke subtype of other determined etiology and undetermined etiology, 3) severe inflammatory disease or autoimmune disease (white blood cells $>1.0 \times 10^{4} \mathrm{~mm}^{3}$, CRP $>3.0 \mathrm{mg} / \mathrm{dl}$ ), and 4) use of steroids or non-steroidal anti-inflammatory drugs. This study was conducted in a single hospital, and the study protocol was approved by the St. Marianna University Bioethics Committee (no. 2419). Informed consent to participate was obtained from all patients.

\section{Clinical data collection}

Background factors and laboratory test values were determined for each patient at baseline. Age, sex, presence of hypertension, diabetes mellitus, dyslipidemia, smoking habit (Brinkman index), and history of any cardiovascular events were recorded. Definitions of risk factors were as follows. Hypertension was defined as $\geq 2$ blood pressure measurements of $\geq 140 / 90 \mathrm{mmHg}$ or previous diagnosis of hypertension and use of antihypertensive agents. Diabetes was considered to be present if the patient showed an $\mathrm{HbA} 1 \mathrm{c} \geq 6.1 \%$ or if treatment for diabetes was being administered. Abnormal lipid metabolism was defined as total cholesterol $\geq 220 \mathrm{mg} / \mathrm{dL}$, neutral fat levels $\geq 150 \mathrm{mg} / \mathrm{dL}$, HDL cholesterol $<40 \mathrm{mg} / \mathrm{dL}$, or use of oral statin agents.

\section{MRI imaging}

Black-blood (BB) carotid artery MRI was performed on a 1.5-T scanner (Achieva Nova Dual; Philips Healthcare, Best, the Netherlands) using a 16channel NV coil. For positioning of greatest wall thickness, a standard imaging protocol was used, i.e., time-of-flight (TOF), T1-weighted, and T2-weighted. For short-axis T1-weighted images (2-dimensional turbo spin-echo), the parameters were recovery time (TR) 1 cardiac cycle (1 R-R interval), echo time (TE) $15 \mathrm{~ms}$, matrix $153 \times 192$, thickness $3 \mathrm{~mm}$, field of view (FOV) $150 \mathrm{~mm}$, number of samples (NSA) 6, and fat saturation (+). For short-axis T2-weighted images (2D-TSE), parameters were TR 2 cardiac cycles (2 R-R intervals), TE $80 \mathrm{~ms}$, matrix $153 \times 192$, thickness $3 \mathrm{~mm}$, FOV $150 \mathrm{~mm}$, NSA 8, and fat saturation (+). For TOF 2D-TSE, parameters were TR $23 \mathrm{~ms}$, TE $6.9 \mathrm{~ms}$, matrix $120 \times 240$, thickness $1.25 \mathrm{~mm}$, number of excitations 1 , and fat saturation (+).

TOF, T1-weighted, and T2-weighted images were used for the characterization of carotid plaques. The signal intensity ratio relative to the ipsilateral sternocleidomastoid muscle (plaque/muscle ratio) was calculated, and high intensity was defined as a plaque/muscle ratio $>2^{19}$. Plaque characteristics were 
classified into 3 categories: 1) fibrous tissue, 2) lipid/ necrotic core, and 3) intra-plaque hemorrhage ${ }^{4)}$ (Figure 1). To test interobserver reliability, the intraclass correlation coefficient (ICC) was calculated for three assessors (ICC $=0.791,0.360-0.944)$.

\section{Ultrasonography}

Carotid US with a $7.5-\mathrm{MHz}$ linear probe (SSA-770A Aplio or SSA-660A Xario; Toshiba Medical, Tokyo, Japan, and HDI-3000; Hitachi, Tokyo, Japan) was performed within 3 months before or after the BB-MRI examination. B-mode imaging, color and power Doppler imaging, and CEUS were performed using Sonazoid (perfluorobutane microbubbles; Daiichi Sankyo Pharmaceutical, Tokyo, Japan). Maximum percent area stenosis (\%AS) was calculated from measurements on serial cross-sectional images by B-mode ultrasonography using the following formula:
$\% \mathrm{AS}=[1-($ area of residual lumen/area of normal vessel) $] \times 100$.

If the \%AS was greater than $50 \%$, the patient was enrolled in this study, and peak systolic flow velocity at the stenotic lesion was recorded. Intima-media thickness (IMT) was measured in the posterior wall of each carotid artery as the distance between the leading edge of the first and second echogenic lines. Maximum IMT (maxIMT) was determined as the larger IMT of the two carotid arteries (common and internal carotid arteries). Carotid plaques were classified into two groups: hypoechoic plaque or nonhypoechoic plaque.

A total of $16 \mu \mathrm{L}$ of Sonazoid was dissolved in 2 $\mathrm{mL}$ of water, and an intravenous bolus injection of the contrast agent suspension was injected into the antecubital vein for a dose of $0.15 \mathrm{~mL} / \mathrm{kg}$. The acoustic power for harmonic US was set with a mechanical index of $0.2-0.3$, depth $3 \mathrm{~cm}$, and focus $2.5 \mathrm{~cm}$. Car-
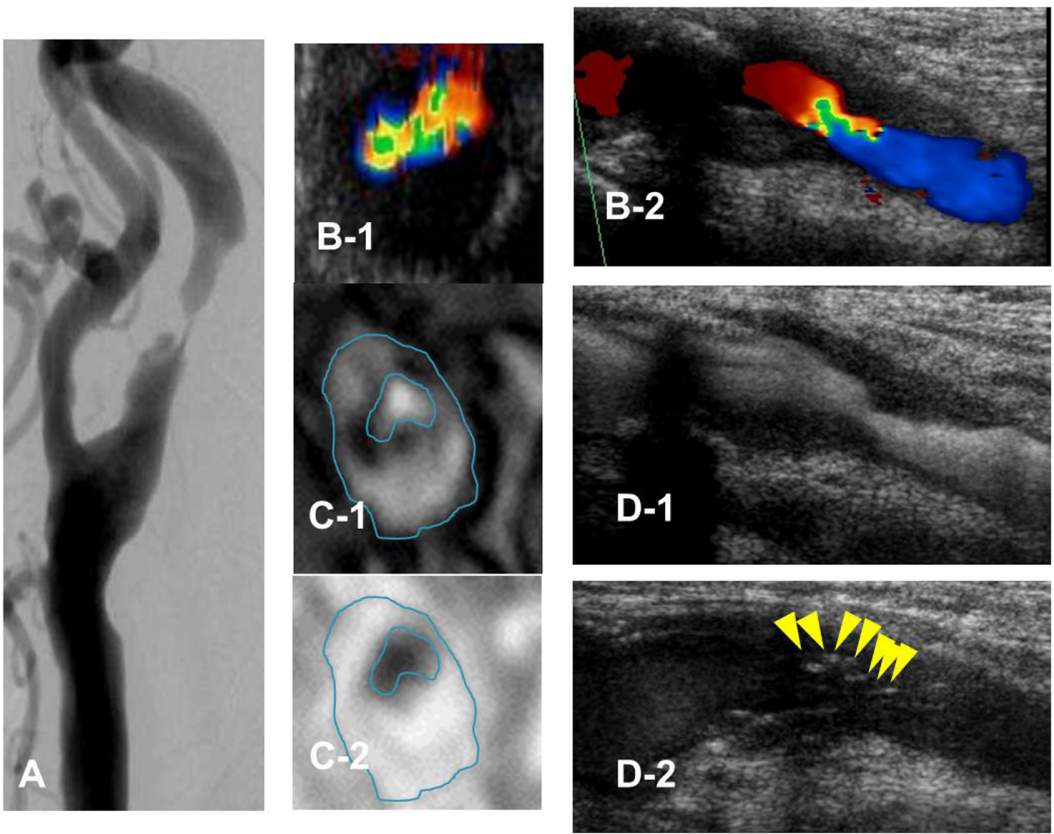

Figure 1. Characterization of carotid plaque by black-blood magnetic resonance imaging and contrast-enhanced ultrasonography (CEUS) imaging

A. Angiogram of the left internal carotid artery (ICA) showing high-grade stenosis.

B. Color-coded duplex ultrasound of the ICA with hypoechoic atherosclerotic plaque.

C. The plaque shows high signal intensity on time-of-flight magnetic resonance angiography $(\mathrm{C}-1)$, and $\mathrm{T} 1$-weighted imaging $(\mathrm{C}-2)$.

D. Sonazoid (CEUS) showing punctate contrast enhancement in the plaque 
otid plaque was evaluated from the longitudinal and transverse views for about $5 \mathrm{~min}$ after contrast injection. Presence of an enhanced lesion was identified based on echogenic reflectors of microbubbles in the plaque (Figure 1). The kappa coefficient for diagnostic concordance of hypoechoic plaque between two examiners was 0.750 .

\section{Measurements of biomarkers}

All blood samples were centrifuged at $3000 \mathrm{rpm}$ for $10 \mathrm{~min}$ at $4^{\circ} \mathrm{C}$. Serum and plasma were separated and stored at $-80^{\circ} \mathrm{C}$ until analysis. Levels of hs-CRP, MMP-9, PTX-3, and MPO were measured in duplicate using commercially available ELISA kits: the CardioPhase High-sensitivity C-Reactive Protein system (Siemens Medical Solutions, Erlangen, Germany), the human MMP-9 ELISA System (GE Healthcare, Buckinghamshire, UK), the Human Pentraxin3 ELISA System, (Perseus Proteomics, Tokyo, Japan), and the Human MPO ELISA System (Mercodia AB, Uppsala, Sweden). Serum sLOX-1 levels were measured by an enzyme immunoassay, as previously described ${ }^{20)}$, except that immobilized mouse monoclonal anti-sLOX-1 and 96-well EIA plates (Corning, NY) were used. Serum levels of LOX-1 ligand containing apoB (LAB) were measured by an enzyme immunoassay with immobilized recombinant LOX-1, as previously described ${ }^{20)}$, except that a chimeric standard protein $^{21}$ and 96-well EIA plates (Greiner, Kremsmuenster, Austria) were used.

\section{Statistical analyses}

Characteristics of the patients are presented as means and standard deviation unless otherwise indicated. Multivariate logistic regression analysis was performed to determine which baseline characteristics were independently associated with intra-plaque hemorrhage on MRI and intra-plaque neovascularization on CEUS. Variables were included in this model if univariate $p$-values were less than 0.1. A two-sided $p$-value less than 0.05 was considered significant. All statistical analyses were performed using SPSS version 22 (IBM SPSS Statistics for Windows; IBM Corp, Armonk, NY).

\section{Results}

Patient demographics and clinical characteristics including carotid US findings, BB-MRI plaque findings, and values of circulating biomarkers are shown in Table 1. MRI diagnoses of plaque characteristics were as follows: fibrous tissue, $n=13$; lipid/necrotic core, $n=30$; and intra-plaque hemorrhage, $n=8$. The odds ratios (ORs) and $95 \%$ confidence intervals $(95 \%$ CIs) of each parameter for predicting intra-plaque hemorrhage by BB-MRI and intra-plaque neovascularization by CEUS are shown in Table 2 . Figures 2 and $\mathbf{3}$ show plots of the respective biomarkers in the presence or absence of intra-plaque hemorrhage and intra-plaque neovascularization. Although the difference was not statistically significant, the serum hsCRP level tended to be high in intra-plaque hemorrhage and intra-plaque neovascularization. In intraplaque hemorrhage, univariate logistic regression analyses revealed three factors with $p$-values less than 0.1: brain hemorrhage, hypoechoic plaque, and serum hs-CRP. Multivariate logistic regression analysis showed that hypoechoic plaque (OR 63.126, 95\% CI 1.102-3616.91) and serum hs-CRP (OR 1.064, 95\% CI 1.002-1.130) were significantly associated with intra-plaque hemorrhage (Table 3). Similarly, multivariate logistic regression analysis of factors associated with intra-plaque neovascularization identified hypoechoic plaque on carotid US (OR 30.362, 95\% CI 2.462-374.37) and serum hs-CRP (OR 1.066, 95\% CI 1.003-1.132) as significant factors (Table 4). No other biomarkers were predictive of imaging characteristics of plaque instability in MRI-BB and CEUS.

\section{Discussion}

Previously described pathological features of vulnerable plaques have included a thin fibrous cap with a large lipid core, intra-plaque hemorrhage, specific luminal surface morphology such as irregular and ulcerated areas, and active intra-plaque inflammation $^{22)}$. These pathological features can be evaluated by several imaging modalities, such as positron emission tomography ${ }^{23)}$, computed tomographic angiography, $\mathrm{MRI}^{24)}$, and CEUS ${ }^{25}$. In this study, intraplaque hemorrhage was detected by MRI plaque imaging. CEUS has recently been used to visualize intra-plaque neovascularization as an element of plaque vulnerability ${ }^{10)}$.

As a plaque forms and enlarges and luminal stenosis progresses, regional blood flow velocity and shear stress increase. High shear stress is associated with a large lipid core and plaque instability ${ }^{23}$. Plaque rupture occurs at sites with excessive shear stress $^{2728)}$, and areas where shear stress is concentrated tend to become future plaque rupture points ${ }^{29)}$. Shear stress has been identified as a trigger for the development of arteriogenesis and neovasculariza- 
Table 1. Demographic and Clinical Characteristics of Study Patients

\begin{tabular}{|c|c|}
\hline Characteristic & $\begin{array}{c}\text { Patients } \\
(\mathrm{n}=51)\end{array}$ \\
\hline Male, n (\%) & $43(84.3)$ \\
\hline Age, years & $73.5 \pm 9.4$ \\
\hline \multicolumn{2}{|l|}{ Comorbidity, n (\%) } \\
\hline Hypertension & $44(86.3)$ \\
\hline Dyslipidemia & $27(52.9)$ \\
\hline Diabetes mellitus & $17(33.3)$ \\
\hline Smoking (Brinkman index) & $760.4 \pm 665.5$ \\
\hline \multicolumn{2}{|l|}{ Cerebrovascular disease, $\mathrm{n}(\%)$} \\
\hline TIA & $4(7.8)$ \\
\hline Brain infarction & $20(39.2)$ \\
\hline Brain hemorrhage & $4(7.8)$ \\
\hline Coronary artery disease, $\mathrm{n}(\%)$ & $11(21.6)$ \\
\hline Peripheral artery disease, $\mathrm{n}(\%)$ & $8(15.7)$ \\
\hline Chronic kidney disease, n (\%) & $14(27.5)$ \\
\hline Systolic blood pressure, $\mathrm{mmHg}$ & $142.2 \pm 26.0$ \\
\hline Diastolic blood pressure, $\mathrm{mmHg}$ & $75.5 \pm 14.4$ \\
\hline Total cholesterol, mg/dL & $176.3 \pm 39.4$ \\
\hline Triglyceride, $\mathrm{mg} / \mathrm{dL}$ & $115.5 \pm 66.0$ \\
\hline HDL cholesterol, mg/dL & $49.5 \pm 15.5$ \\
\hline LDL cholesterol, mg/dL & $104.9 \pm 32.0$ \\
\hline Blood sugar, $\mathrm{mg} / \mathrm{dL}$ & $133.4 \pm 46.1$ \\
\hline $\mathrm{HbA} 1 \mathrm{c}, \%$ & $6.2 \pm 0.9$ \\
\hline \multicolumn{2}{|l|}{ Current medications, $\mathrm{n}(\%)$} \\
\hline Statin & $24(47.1)$ \\
\hline \multicolumn{2}{|l|}{ Carotid ultrasound findings } \\
\hline Area ratio $(\%)$ & $75.6 \pm 12.2$ \\
\hline Peak systolic flow $(\mathrm{cm} / \mathrm{s})$ & $164.4 \pm 121.9$ \\
\hline $\operatorname{Max} \operatorname{IMT}(\mathrm{mm})$ & $4.3 \pm 1.2$ \\
\hline \multicolumn{2}{|l|}{ Morphology of plaque, n (\%) } \\
\hline Heterogeneous & $20(39.2)$ \\
\hline Hypoechoic & $24(47.1)$ \\
\hline \multicolumn{2}{|l|}{ BB-MRI plaque findings, $\mathbf{n}(\%)$} \\
\hline Fibrous tissue & $13(25.5)$ \\
\hline Lipid/necrotic core & $30(58.8)$ \\
\hline Intra-plaque hemorrhage & $8(15.7)$ \\
\hline \multicolumn{2}{|l|}{ Biomarker } \\
\hline $\mathrm{LAB}(\mathrm{mg} \mathrm{cs} / \mathrm{L})$ & $5.9 \pm 3.0$ \\
\hline sLOX-1 (ng/L) & $1402.4 \pm 952.8$ \\
\hline $\mathrm{MPO}(\mu \mathrm{g} / \mathrm{L})$ & $91.4 \pm 65.8$ \\
\hline PTX3 (ng/mL) & $4.1 \pm 4.0$ \\
\hline MMP-9 (ng/mL) & $10.2 \pm 5.1$ \\
\hline Hs-CRP (ng/mL) & $7775.5 \pm 16624.6$ \\
\hline
\end{tabular}

TIA, transient ischemic attack; HDL, high-density lipoprotein; LDL, low-density lipoprotein; max IMT, maximum value of intima media thickness; BB-MRI, black-blood MR imaging; LAB, LOX-1 ligand containing apoB; sLOX, soluble form of lectin-like oxidized LDL receptor 1; MPO, myeloperoxidase; PTX3, pentraxin3; MMP-9, matrix metalloproteinase-9; hs-CRP, high-sensitivity C-reactive protein.

$\operatorname{tion}^{30)}$. However, our study demonstrated that the hypoechoic nature of the plaque and hs-CRP levels were also factors commonly associated with intraplaque hemorrhage and intra-plaque neovascularization. These results are reasonable because inflammation of carotid plaque may play an important role in developing plaque instability that is independent of the severity of stenosis.

Several promising biomarkers predictive of plaque instability have been found. Hayashida et al. reported that serum sLOX-1 levels were significantly higher in patients with acute coronary syndrome 
Table 2. Univariate Odds Ratio of Confounders for Intra-plaque Hemorrhage on Black-blood MRI and Intra-plaque Neovascularization on Contrast-enhanced Carotid Ultrasound

\begin{tabular}{|c|c|c|c|c|c|c|c|c|}
\hline \multirow{3}{*}{ Age } & \multicolumn{4}{|c|}{$\begin{array}{c}\text { Intra-plaque hemorrhage (+) } \\
\text { Univariate analysis }\end{array}$} & \multicolumn{4}{|c|}{$\begin{array}{c}\text { Intra-plaque neovascularization (+) } \\
\text { Univariate analysis }\end{array}$} \\
\hline & \multirow{2}{*}{$\begin{array}{l}\text { OR } \\
.977\end{array}$} & \multicolumn{2}{|c|}{$95 \% \mathrm{CI}$} & \multirow{2}{*}{$\begin{array}{c}\mathrm{p} \\
.551\end{array}$} & \multirow{2}{*}{$\begin{array}{l}\text { OR } \\
.964\end{array}$} & \multicolumn{2}{|c|}{$95 \%$ CI } & \multirow{2}{*}{$\frac{\mathrm{p}}{.267}$} \\
\hline & & .907 & 1.054 & & & .903 & 1.029 & \\
\hline Male sex & - & .000 & - & .999 & - & .000 & & .999 \\
\hline \multicolumn{9}{|l|}{ Comorbidity } \\
\hline Hypertension & .395 & .062 & 2.516 & .325 & .444 & .086 & 2.303 & .334 \\
\hline Dyslipidemia & .870 & .192 & 3.936 & .856 & .850 & .248 & 2.911 & .796 \\
\hline Diabetes mellitus & .000 & .000 & - & .998 & .738 & .193 & 2.825 & .658 \\
\hline Smoking (Brinkman index) & 1.000 & .999 & 1.002 & .353 & 1.000 & .999 & 1.001 & .449 \\
\hline \multicolumn{9}{|l|}{ Cerebrovascular disease } \\
\hline TIA & .000 & .000 & - & .999 & .872 & .083 & 9.157 & .909 \\
\hline Brain infarction & 3.111 & .652 & 14.845 & .155 & .525 & .139 & 1.984 & .342 \\
\hline Brain hemorrhage & 6.833 & .805 & 58.022 & .078 & 2.917 & .369 & 23.038 & .310 \\
\hline Coronary artery disease & .471 & .052 & 4.304 & .505 & .519 & .097 & 2.768 & .442 \\
\hline Peripheral artery disease & .735 & .078 & 6.945 & .788 & .000 & .000 & - & .999 \\
\hline Chronic kidney disease & .330 & .037 & 2.958 & .322 & .645 & .150 & 2.771 & .555 \\
\hline $\begin{array}{l}\text { Systolic blood pressure } \\
(\mathrm{mmHg})\end{array}$ & 1.004 & .975 & 1.034 & .792 & .997 & .974 & 1.022 & .831 \\
\hline $\begin{array}{l}\text { Diastolic blood pressure } \\
(\mathrm{mmHg})\end{array}$ & 1.027 & .976 & 1.081 & .301 & 1.022 & .980 & 1.067 & .309 \\
\hline Total cholesterol (mg/dl) & 1.002 & .983 & 1.022 & .833 & .994 & .979 & 1.010 & .487 \\
\hline Triglyceride (mg/dl) & 1.004 & .993 & 1.014 & .496 & 1.000 & .991 & 1.010 & .959 \\
\hline HDL cholesterol (mg/dl) & .986 & .933 & 1.041 & .599 & .994 & .953 & 1.035 & .757 \\
\hline LDL cholesterol (mg/dl) & .995 & .971 & 1.019 & .675 & .992 & .973 & 1.012 & .424 \\
\hline Blood sugar $(\mathrm{mg} / \mathrm{dl})$ & 1.000 & .983 & 1.017 & .991 & 1.002 & .990 & 1.015 & .721 \\
\hline $\mathrm{HbA1c}$ & .396 & .088 & 1.782 & .227 & .958 & .497 & 1.847 & .898 \\
\hline \multicolumn{9}{|l|}{ Current medications } \\
\hline Statin & 4.167 & .735 & 23.064 & .102 & 1.176 & .343 & 4.029 & .796 \\
\hline \multicolumn{9}{|l|}{ Carotid ultrasound findings } \\
\hline Area ratio & .992 & .932 & 1.055 & .796 & 1.058 & .997 & 1.124 & .064 \\
\hline Peak systolic flow $(\mathrm{cm} / \mathrm{sec})$ & 1.004 & .998 & 1.009 & .212 & 1.010 & 1.004 & 1.017 & .001 \\
\hline Max IMT & .846 & .442 & 1.618 & 613 & 1.460 & .882 & 2.417 & .141 \\
\hline \multicolumn{9}{|l|}{ Plaque morphology } \\
\hline Heterogeneous & 0.918 & .194 & 4.351 & .914 & .525 & .139 & 1.984 & .342 \\
\hline Hypoechoic plaque & 10.706 & 1.207 & 94.959 & .033 & 12.500 & 2.406 & 64.932 & .003 \\
\hline $\begin{array}{l}\text { Intra-plaque } \\
\text { neovascularization }\end{array}$ & 3.30 & .696 & 15.642 & .133 &. & - & - & - \\
\hline \multicolumn{9}{|l|}{ BB-MRI plaque findings } \\
\hline Fibrous tissue & 0.000 & 0.000 & 0.000 & 0.999 & 1.244 & .313 & 4.954 & .756 \\
\hline Lipid/necrotic core & 0.000 & 0.000 & 0.000 & 0.998 & .406 & .116 & 1.426 & .160 \\
\hline Intra-plaque hemorrhage & - & - & - & - & .330 & .696 & 15.642 & .133 \\
\hline \multicolumn{9}{|l|}{ Biomarkers } \\
\hline Serum $\mathrm{LAB}(\mathrm{mg} \mathrm{cs} / \mathrm{L})$ & 0.925 & 0.703 & 1.217 & .579 & .796 & 612 & 1.037 & .091 \\
\hline Serum LOX-1 (ng/L) & 1.000 & .999 & 1.001 & .591 & 1.000 & .999 & 1.001 & .950 \\
\hline Plasma MPO $(\mu \mathrm{g} / \mathrm{L})$ & 1.001 & .990 & 1.012 & .833 & 1.006 & .997 & 1.014 & .221 \\
\hline Plasma PTX3 (ng/mL) & 1.004 & .833 & 1.209 & .970 & .895 & .696 & 1.150 & .385 \\
\hline Serum MMP-9 (ng/mL) & 1.063 & .923 & 1.224 & .398 & .991 & .877 & 1.120 & .886 \\
\hline Serum hs-CRP (mg/mL) & 1.034 & 0.995 & 1.075 & .091 & 1.035 & 0.994 & 1.077 & .092 \\
\hline
\end{tabular}

TIA, transient ischemic attack; US, ultrasound; HDL, high-density lipoprotein; LDL, low- density lipoprotein; IMT,

maximum-intima-media thickness; BB-MRI, black-blood magnetic resonance imaging; LAB, LOX-1 ligand containing apoB; sLOX-1, soluble form of lectin-like oxidized LDL receptor 1; MPO, myeloperoxidase; PTX3, pentraxin 3; MMP-9, matrix metalloproteinase 9; hs-CRP, high-sensitivity C-reactive protein.

(ACS) than in patients without ACS, and the sensitivity and specificity of sLOX-1 $>1.0 \mathrm{ng} / \mathrm{mL}$ for the diagnosis of ACS were reported to be $81 \%$ and $75 \%$, respectively ${ }^{14}$. MMP-9 is a zinc-dependent endopeptidase that degrades the extracellular matrix, and this enzyme is elevated in culprit lesions. Alvarez et al. ${ }^{31}$ demonstrated a significant increase of serum MMP-9 concentrations in patients with symptomatic carotid artery stenosis and suggested MMP-9 as a biomarker of carotid plaque instability. Brennan et al. ${ }^{17)}$ assessed the value of plasma levels of MPO in 604 consecutive patients with chest pain and reported that a single initial measurement of plasma MPO independently predicted early risk for myocardial infarction. Plasma 

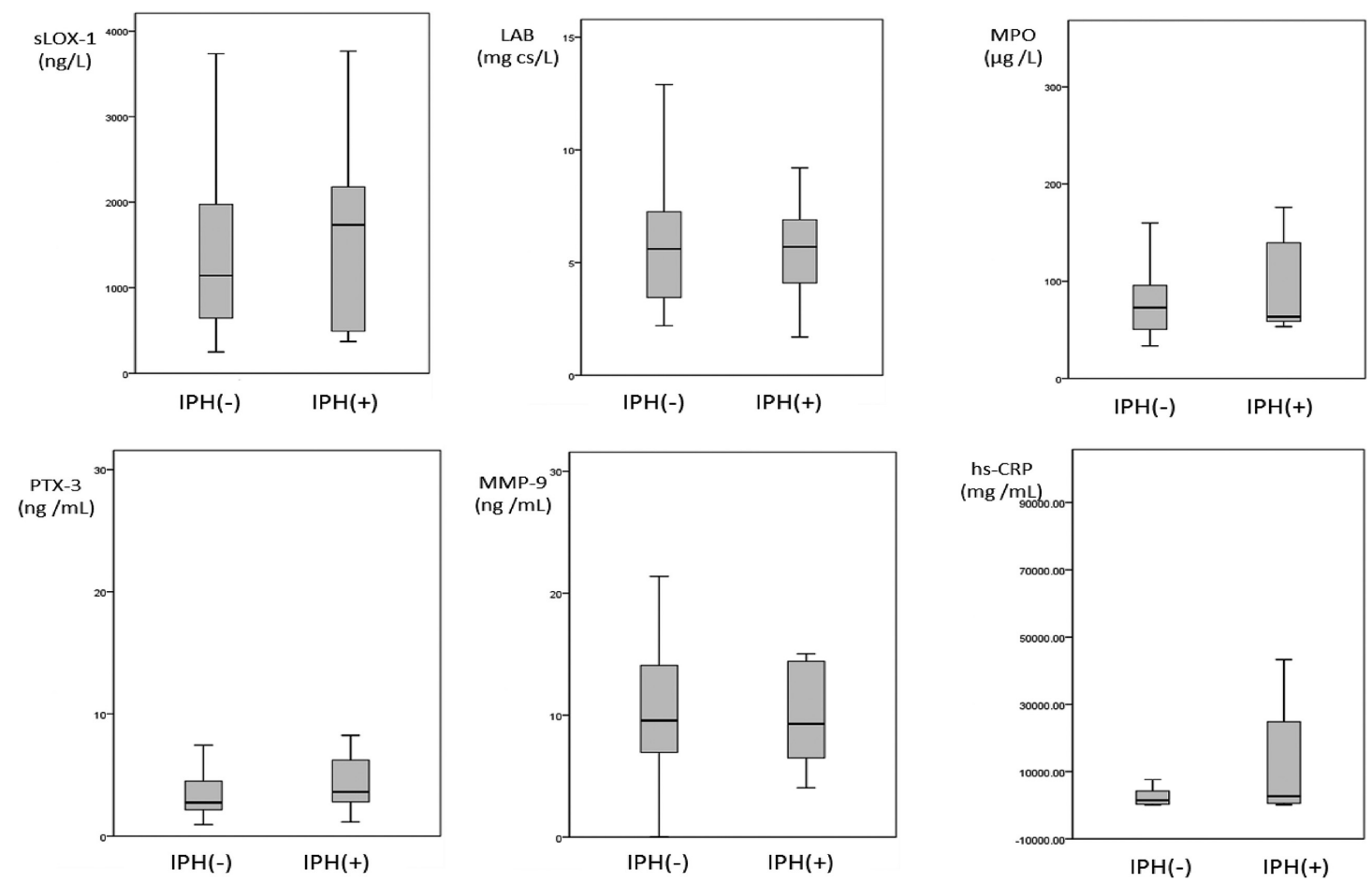

Figure 2. Box and whiskers plots of biomarker levels in intra-plaque hemorrhage

Box plots showing the distribution of biomarker levels by according to the presence or absence of intra-plaque hemorrhage. IPH, intra-plaque hemorrhage; LAB, LOX-1 ligand containing apoB; sLOX-1, soluble form of lectin-like oxidized LDL receptor 1; MPO, myeloperoxidase; PTX3, pentraxin 3; MMP-9, matrix metalloproteinase 9; hs-CRP, high-sensitivity C-reactive protein.

levels of PTX3 are associated with the presence of atherosclerotic plaques and prevalent vascular disease $^{13322)}$, and abundant localization of PTX-3 in areas of intra-plaque hemorrhage was demonstrated by immunohistochemistry ${ }^{33)}$. Of these promising biomarkers, only hs-CRP was found to be a biomarker predictive of intra-plaque hemorrhage and intra-plaque neovascularization by multivariate logistic regression analysis in the present study.

The source of neovascularization is direct branching from the vasa vasorum or intimal surface. These areas are very fragile, and plaque hemorrhage can easily occur ${ }^{3435)}$. Evaluation of neovascularization is therefore important in assessing plaque instability. Currently, to the best of our knowledge, only a few studies have assessed the association between carotid artery plaque neovascularization and circulating biomarker levels. Serum levels of CD146 ${ }^{36}$ and vascular endothelial growth factor ${ }^{37)}$ have recently been reported as biomarkers associated with histologically determined neovascularization. Jaipersad et al. ${ }^{38)}$ demonstrated correlations between the levels of
CD14+/CD16-/CCR2+ monocytes and intra-plaque neovascularization on CEUS. Further studies are necessary to identify the best biomarker to predict intraplaque neovascularization and intra-plaque hemorrhage.

It is reasonable to assume that microvessels formed in plaque are prone to rupture, but no significant association between intra-plaque neovascularization and intra-plaque hemorrhage was observed in the present cross-sectional study. Hypoechoic plaques seen on carotid US are pathologically associated with large lipid cores and intra-plaque hemorrhage and are widely recognized as plaques that confer a high risk of cerebral infarction ${ }^{23339)}$. However, distinguishing between lipid cores and intra-plaque hemorrhage is often difficult on the basis of hypoechoic findings alone. Further longitudinal follow-up studies are needed to verify whether the evaluation of echogenicity, peak systolic flow velocity, intra-plaque neovascularization, and hs-CRP levels could be used to identify carotid plaque instability.

This study has several limitations. First, the con- 

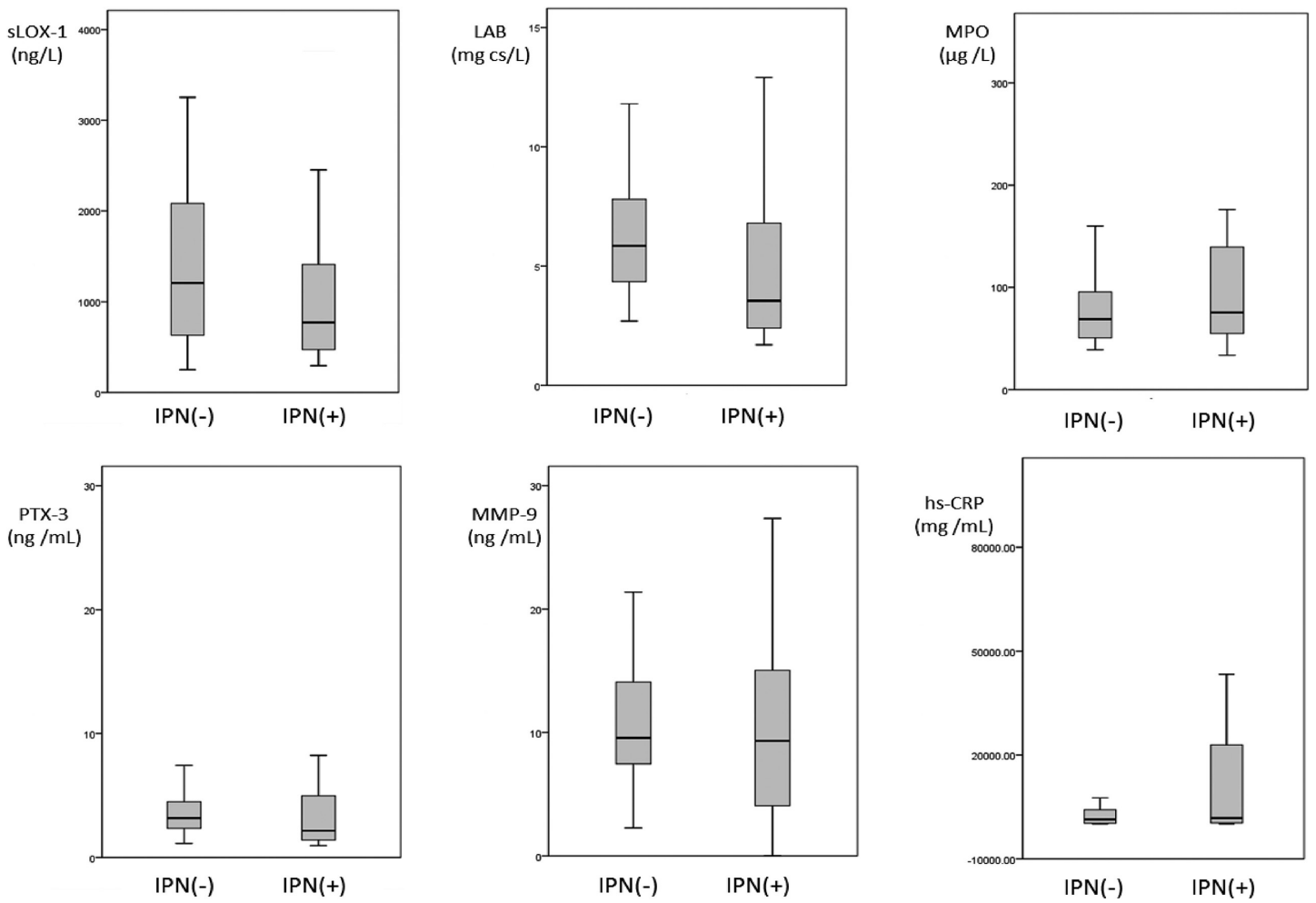

Figure 3. Box and whiskers plots of biomarker levels in intra-plaque neovascularization

Box plot showing the distribution of biomarker levels according to the presence or absence of intra-plaque neovascularization. IPN, intra-plaque neovascularization; LAB, LOX-1 ligand containing apoB; sLOX-1, soluble form of lectin-like oxidized LDL receptor 1; MPO, myeloperoxidase; PTX3, pentraxin 3; MMP-9, matrix metalloproteinase 9; hs-CRP, high-sensitivity C-reactive protein.

Table 3. Multivariate Logistic Regression Analysis for Intra-plaque Hemorrhage on Black-blood Magnetic Resonance Imagimg

\begin{tabular}{lcccc}
\hline & \multicolumn{4}{c}{ Multivariate analysis } \\
\cline { 2 - 5 } & OR & \multicolumn{2}{c}{$95 \%$ CI } & $\mathrm{p}$ \\
\hline Brain hemorrhage & 10.768 & 0.387 & 299.38 & 0.161 \\
Hypoechoic plaque & 63.126 & 1.102 & 3616.91 & $\mathbf{0 . 0 4 5}$ \\
Serum hs-CRP (mg/mL) & 1.064 & 1.002 & 1.130 & $\mathbf{0 . 0 4 1}$ \\
\hline hs-CRP, high-sensitivity C-reactive protein; OR, odds ratio; CI, confidence interval.
\end{tabular}

trast effect with Sonazoid is caused by presence in the plaque of echogenic reflectors of microbubbles; therefore, the more hypoechoic a plaque, the easier it may be to assess these contrast effects, and this may have influenced our results. However, hyperechoic plaques are widely known to be associated with a lower risk of vascular events than hypoechoic plaques, so this does not negate the value of the CEUS findings. Echogenicity in this study was initially evaluated qualitatively by an examiner without using a quantitative technique such as a gray-scale median ${ }^{40)}$ or integrated backscatter ${ }^{41)}$. However, screening studies for unstable plaques are also usually qualitative. In a longitudinal study to investigate changes over time in plaque brightness, a quantitative method would be required. Second, imaging to evaluate fibrous cap thinning or rupture was not performed. Intra-plaque hemorrhage is followed by plaque rupture in the process leading to cerebral infarction, and fibrous cap rupture is an essential feature. The addition of MRI to evaluate the fibrous cap is clinically important and would be highly valuable in future studies. 
Table 4. Multivariate Logistic Regression Analysis for Intra-plaque Neovascularization on Contrast-enhanced Carotid Ultrasound

\begin{tabular}{lcccc}
\hline & \multicolumn{4}{c}{ Multivariate analysis } \\
\cline { 2 - 5 } & OR & \multicolumn{2}{c}{ 95\%CI } & $\mathrm{p}$ \\
\hline Area ratio & 1.011 & 0.916 & 1.116 & 0.828 \\
Peak systolic flow (cm/sec) & 5.644 & 0.608 & 52.38 & 0.128 \\
Hypoechoic plaque & 30.362 & 2.462 & 374.37 & $\mathbf{0 . 0 0 8}$ \\
Serum LAB $(\mathrm{mg} \mathrm{cs} / \mathrm{L})$ & 0.975 & 0.695 & 1.370 & 0.886 \\
Serum hs-CRP $(\mathrm{ng} / \mathrm{mL})$ & 1.066 & 1.003 & 1.132 & $\mathbf{0 . 0 4 0}$ \\
\hline LAB, LOX-1 ligand containing apoB; hs-CRP, high-sensitivity C-reactive protein; OR, \\
odds ratio; CI, confidence interval.
\end{tabular}

Third, this study used MRI to evaluate intra-plaque hemorrhage and the lipid core, but pathological studies to confirm these findings were not performed in any patient. Future studies should include correlation with pathological findings.

\section{Conclusion}

In conclusion, hypoechoic plaque and hs-CRP levels were found to be factors commonly predictive of intra-plaque hemorrhage and intra-plaque neovascularization. Further longitudinal studies are necessary to clarify the roles of intra-plaque neovascularization and hs-CRP levels in intra-plaque hemorrhage.

\section{Disclosures}

Kagehiro Uchida is an employee of Biomarker Science. The other authors report no conflicts.

\section{References}

1) Brott TG, Halperin JL, Abbara S, Bacharach JM, Barr JD, Bush RL, Cates CU, Creager MA, Fowler SB, Friday G, Hertzberg VS, McIff EB, Moore WS, Panagos PD, Riles TS, Rosenwasser RH, Taylor AJ, Jacobs AK, Smith SC Jr, Anderson JL, Adams CD, Albert N, Buller CE, Creager MA, Ettinger SM, Guyton RA, Halperin JL, Hochman JS, Hunt SA, Krumholz HM, Kushner FG, Lytle BW, Nishimura RA, Ohman EM, Page RL, Riegel B, Stevenson WG, Tarkington LG, Yancy CW. 2011 ASA/ ACCF/AHA/AANN/AANS/ACR/ASNR/CNS/ SAIP/SCAI/SIR/SNIS/SVS guideline on the management of patients with extracranial carotid and vertebral artery disease: executive summary: a report of the American College of Cardiology Foundation/American Heart Association Task Force on Practice Guidelines, and the American Stroke Association, American Association of Neuroscience Nurses, American Association of Neurological Surgeons, American Col- lege of Radiology, American Society of Neuroradiology, Congress of Neurological Surgeons, Society of Atherosclerosis Imaging and Prevention, Society for Cardiovascular Angiography and Interventions, Society of Interventional Radiology, Society of NeuroInterventional Surgery, Society for Vascular Medicine, and Society for Vascular Surgery. Developed in collaboration with the American Academy of Neurology and Society of Cardiovascular Computed Tomography. Catheter Cardiovasc Interv 2013; 81: E76-E123.

2) Mathiesen EB, Bønaa KH, Joakimsen O. Echolucent plaques are associated with high risk of ischemic cerebrovascular events in carotid stenosis; the Trømso study. Circulation 2001; 103: 2171-2175.

3) Grønholdt ML, Nordestgaard BG, Schroeder TV, Vorstrup S, Sillesen H. Ultrasonic echolucent carotid plaques predict future strokes. Circulation 2001; 104: 68-73.

4) Yuan C, Mitsumori LM, Ferguson MS, Polissar NL, Echelard D, Ortiz G, Small R, Davies JW, Kerwin WS, Hatsukami TS. In vivo accuracy of multispectral magnetic resonance imaging for identifying lipid-rich necrotic cores and intraplaque hemorrhage in advanced human carotid plaques. Circulation 2001; 104: 2051-2056.

5) Takaya N, Yuan C, Chu B, Saam T, Polissar NL, Jarvik GP, Isaac C, McDonough J, Natiello C, Small R, Ferguson MS, Hatsukami TS. Presence of intraplaque hemorrhage stimulates progression of carotid atherosclerotic plaques: a highresolution magnetic resonance imaging study. Circulation 2005; 111: 2768-2775.

6) Altaf N, Daniels L, Morgan PS, Auer D, MacSweeney ST, Moody AR, Gladman JR. Detection of intraplaque hemorrhage by magnetic resonance imaging in symptomatic patients with mild to moderate carotid stenosis predicts recur- 
rent neurological events. J Vasc Surg 2008; 47: 337-342.

7) Altaf N, MacSweeney ST, Gladman J, Auer DP. Carotid intraplaque hemorrhage predicts recurrent symptoms in patients with high-grade carotid stenosis. Stroke 2007; 38: 1633-1635.

8) Barger AC, Beeuwkes R 3rd, Lainey LL, Silverman KJ. Hypothesis: vasa vasorum and neovascularization of human coronary arteries: a possible role in the pathophysiology of atherosclerosis. N Engl J Med 1984; 310: 175177.

9) Kolodgie FD, Gold HK, Burke AP, Fowler DR, Kruth HS, Weber DK, Farb A, Guerrero LJ, Hayase M, Kutys R, Narula J, Finn AV, Virmani $\mathrm{R}$. Intraplaque hemorrhage and progression of coronary atheroma. N Engl J Med 2003; 349: 2316-2325.

10) Alonso A, Artemis D, Hennerici MG. Molecular imaging of carotid plaque vulnerability. Cerebrovasc Dis 2015; 39: 5-12.

11) Pini R, Faggioli G, Fittipaldi S, Pasquinelli G, Tonon C, Beltrandi E, Mauro R, Stella A. Inflammatory mediators and cerebral embolism in carotid stenting: new markers of risk. J Endovasc Ther. 2013; 20: 684-694.

12) Krupinski J, Turu MM, Martinez-Gonzalez J, Carvajal A, Juan-Babot JO, Iborra E, Slevin M, Rubio F, Badimon L. Endogenous expression of C-reactive protein is increased in active (ulcerated noncomplicated) human carotid artery plaques. Stroke 2006; 37: 1200-1204.

13) Shindo A, Tanemura H, Yata K, Hamada K, Shibata M, Umeda Y, Asakura F, Toma N, Sakaida H, Fujisawa T, Taki W, Tomimoto H. Inflammatory biomarkers in atherosclerosis: pentraxin 3 can become a novel marker of plaque vulnerability. PLoS One 2014; 9: e100045.

14) Hayashida K, Kume N, Murase T, Minami M, Nakagawa D, Inada T, Tanaka M, Ueda A, Kominami G, Kambara H, Kimura T, Kita T. Serum soluble lectin-like oxidized low-density lipoprotein receptor-1 levels are elevated in acute coronary syndrome: a novel marker for early diagnosis. Circulation 2005; 112: 812-818.

15) Kai H, Ikeda H, Yasukawa H, Kai M, Seki Y, Kuwahara F, Ueno T, Sugi K, Imaizumi T. Peripheral blood levels of matrix metalloproteases-2 and -9 are elevated in patients with acute coronary syndromes. J Am Coll Cardiol 1998; 32: $368-372$.
16) Inokubo $Y$, Hanada $H$, Ishizaka $H$, Fukushi $T$, Kamada T, Okumura K. Plasma levels of matrix metalloproteinase- 9 and tissue inhibitor of metalloproteinase- 1 are increased in the coronary circulation in patients with acute coronary syndrome. Am Heart J 2001; 141: 211-217.

17) Brennan ML, Penn MS, Van Lente F, Nambi V, Shishehbor MH, Aviles RJ, Goormastic M, Pepoy ML, McErlean ES, Topol EJ, Nissen SE, Hazen SL. Prognostic value of myeloperoxidase in patients with chest pain. N Engl J Med 2003; 349: 1595-1604.

18) Adams HP Jr, Bendixen BH, Kappelle LJ, Biller J, Love BB, Gordon DL, Marsh EE 3rd: Classification of subtype of acute ischemic stroke. Definitions for use in a multicenter clinical trial. TOAST. Trial of Org 10172 in Acute Stroke Treatment. Stroke 1993; 24: 35-41.

19) Narumi S, Sasaki M, Natori T, Yamaguchi Oura M, Ogasawara K, Kobayashi M, Sato Y, Ogasawara Y, Hitomi j, Terayama Y. Carotid plaque characterization using 3D T1-weighted MR imaging with histopathologic validation: a comparison with 2D technique. AJNR Am J Neuroradiol 2015; 36: 751-756.

20) Inoue N, Okamura T, Kokubo Y, Fujita $Y$, Sato Y, Nakanishi M, Yanagida K, Kakino A, Iwamoto S, Watanabe M, Ogura S, Otsui K, Matsuda H, Uchida K, Yoshimoto R, Sawamura T. LOX index, a novel predictive biochemical marker for coronary heart disease and stroke. Clin Chem 2010; 56: 550-558.

21) Iwamoto S, Fujita Y, Kakino A, Yanagida K, Matsuda H, Yoshimoto R, Sawamura T. An alternative protein standard to measure activity of LOX-1 ligand containing apoB (LAB) - utilization of anti-LOX-1 single- chain antibody fused to apoB fragment. Atheroscler Thromb 2011; 18: 818-828.

22) Naghavi M, Libby P, Falk E, Casscells SW, Litovsky S, Rumberger J, Badimon JJ, Stefanadis S, Moreno P, Pasterkamp G, Fayad Z, Stone PH, Waxman S, Raggi P, Madjid M, Zarrabi A, Burke A, Yuan C, Fitzgerald PJ, Siscovick DS, de Korte CL, Aikawa M, Airaksinen KE, Assmann G, Becker CR, Chesebro JH, Farb A, Galis ZS, Jackson C, Jang IK, Koenig W, Lodder RA, March K, Demirovic J, Navab M, Priori SG, Rekhter MD, Bahr R, Grundy SM, Mehran $\mathrm{R}$, Colombo A, Boerwinkle E, Ballantyne C, Insull W Jr, Schwartz RS, Vogel R, Serruys PW, 
Hansson GK, Faxon DP, Kaul S, Drexler H, Greenland P, Muller JE, Virmani R, Ridker PM, Zipes DP, Shah PK, Willerson JT. From vulnerable plaque to vulnerable patient: a call for new definitions and risk assessment strategies: Part I. Circulation 2003; 108: 1664-1672.

23) Marnane M, Merwick A, Sheehan OC, Hannon N, Foran P, Grant T, Dolan E, Moroney J, Murphy S, O'Rourke K, O’Malley K, O'Donohoe $\mathrm{M}$, McDonnell C, Noone I, Barry M, Crowe M, Kavanagh E, O'Connell M, Kelly PJ. Carotid plaque inflammation on 18F-fluorodeoxyglucose positron emission tomography predicts early stroke recurrence. Ann Neuro. 2012; 71 : 709-718.

24) Saba L, Anzidei M, Marincola BC, Piga M, Raz E, Bassareo PP, Napoli A, Mannelli L, Catalano C, Wintermark M. Imaging of the carotid artery vulnerable plaque. Cardiovasc Intervent Radiol 2014; 37: 572-585.

25) Shalhoub J, Owen DR, Gauthier T, Monaco C, Leen EL, Davies AH. The use of contrast enhanced ultrasound in carotid arterial disease. Eur J Vasc Endovasc Surg 2010; 39: 381-387.

26) Samady H, Eshtehardi P, McDaniel MC, Suo J, Dhawan SS, Maynard C, Timmins LH, Quyyumi AA, Giddens DP. Coronary artery wall shear stress is associated with progression and transformation of atherosclerotic plaque and arterial remodeling in patients with coronary artery disease. Circulatio. 2011; 124: 779-788.

27) Groen HC, Gijsen JH, van der Lugt A, Ferguson MS, Hatsukami TS, van der Steen AF, Yuan C, Wentzel JJ. Plaque rupture in the carotid artery is localized at the high shear stress region: a case report. Stroke 2007; 38 :2379-2381.

28) Gijsen FJ, Nieuwstadt HA, Wentzel JJ, Verhagen HJ, van der Lugt A, van der Steen AF. Carotid plaque morphological classification compared with biomechanical cap stress: Implications for a magnetic resonance imagingbased assessment. Stroke 2015; 46: 2124-2128.

29) Fukumoto Y, Hiro T, Fujii T, Hashimoto G, Fujimura J, Okamura T, Matsuzaki M. Localized elevation of shear stress is related to coronary plaque rupture: a 3-dimensional intravascular ultrasound study with in vivo color mapping of shear stress distribution. J Am Coll Cardiol 2008; 51: 645-650.

30) van Royen N, Piek JJ, Buschmann I, Hoefer I, Voskuil M, Schaper W. Stimulation of arterio- genesis; a new concept for the treatment of arterial occlusive disease. Cardiovasc Res 2001; 49: 543-553.

31) Alvarez B, Ruiz C, Chacón P, Alvarez-Sabin J, Matas M. Serum values of metalloproteinase-2 and metalloproteinase- 9 as related to unstable plaque and inflammatory cells in patients with greater than $70 \%$ carotid artery stenosis. J Vasc Surg 2004; 40: 469-475.

32) Knoflach M, Kiechl S, Mantovani A, Cuccovillo I, Bottazzi B, Xu Q, Xiao Q, Gasperi A, Mayr A, Kehrer M, Wileit J, Wick G. Pentraxin-3 as a marker of advanced atherosclerosis results from the Bruneck, ARMY and ARFY Studies. PLoS One 2012; 7: e31474.

33) Matsuura Y, Hatakeyama K, Imamura T, Tsuruda T, Shibata Y, Kodama T, Kitamura K, Asada Y. Different distribution of pentraxin 3 and $\mathrm{C}$-reactive protein in coronary atherosclerotic plaques. J Atheroscler Thromb 2012; 19: 837-845.

34) Faggioli GL, Pini R, Mauro R, Pasquinelli G, Fittipaldi S, Freyrie A, Serra C, Stella A. Identification of carotid 'vulnerable plaque' by contrast-enhanced ultrasonography: correlation with plaque histology, symptoms and cerebral computed tomography. Eur J Vasc Endovasc Surg 2011; 41: 238-248.

35) Matsumoto N, Kimura K, Uno M, Sakai K, Sadahira $\mathrm{Y}$, Nishimura $\mathrm{H}$. Enhanced carotid plaque on contrast-enhanced ultrasound is associated with plaque instability and rupture. Int J Stroke 2012; 7: E12.

36) Qian YN, Luo YT, Duan HX, Feng LQ, Bi Q, Wang YJ, Yan XY. Adhesion molecule CD146 and its soluble form correlate well with carotid atherosclerosis and plaque instability. CNS Neurosci Ther 2014; 20: 438-445.

37) Pelisek J, Well G, Reeps C, Rudelius M, Kuehnl A, Culmes M, Poppert H, Zimmermann A, Berger H, Eckstein HH. Neovascularization and angiogenic factors in advanced human carotid artery stenosis. Circ. 2012; 76: 1274-1282.

38) Jaipersad AS, Shantsila A, Lip GY, Shantsila E. Expression of monocyte subsets and angiogenic markers in relation to carotid plaque neovascularization in patients with pre-existing coronary artery disease and carotid stenosis. Ann Med 2014; 46: 530-538.

39) Grønholdt ML, Wiebe BM, Laursen $H$, Nielsen TG, Schroeder TV, Sillesen H. Lipid-rich caro- 
tid artery plaques appear echolucent on ultrasound B-mode images and may be associated with intraplaque haemorrhage. Eur J Vasc Endovasc Surg 1997; 14: 439-445.

40) Sabetai MM, Tegos TJ, Nicolaides AN, Dhanjil S, Pare GJ, Stevens JM. Reproducibility of computer-quantifi ed carotid plaque echogenicity: can we overcome the subjectivity? Stroke 2000;
31: 2189-2196.

41) Takiuchi S, Rakugi H, Honda K, Masuyama T, Hirata N, Ito H, Sugimoto K, Yanagitani Y, Moriguchi K, Okamura A, Higaki J, Ogihara T. Quantitative ultrasonic tissue characterization can identify high-risk atherosclerotic alteration in human carotid arteries. Circulation 2000; 102: 766-770. 